\title{
Treating rheumatic patients with a malignancy
}

\author{
Katarzyna Elandt ${ }^{1}$ and Daniel Aletaha*2
}

\begin{abstract}
Management of patients with inflammatory rheumatic disease and a history of (or even a current) malignant disease poses some particular challenges. As direct evidence of the risk of (recurrent or de novo) malignancy in patients with a history of malignant disease is scarce, such a risk may be estimated indirectly from the principal carcinogenicity of the respective drug to be used or (also indirectly) from cancer reactivation data from the transplant literature. In general, cancer risk is increased in patients receiving combination immunosuppressive treatment, but the risk in patients receiving individual drugs (with the exception of alkylating agents) remains entirely unclear. Indirect evidence supports the intuitive concept that the risk of cancer decreases over time after a successful cancer treatment. The only two studies in rheumatic patients with a cancer history were small and have not been able to show an increase in cancer reactivation. The risk of reactivation also depends on the site and location of the prior malignancy. In conclusion, the decision to treat a patient with a history of cancer immunosuppressively should be shared by the rheumatologist and the oncologist. Once the decision is established, such patients need intensive and close monitoring.
\end{abstract}

\section{Defining the problem}

Rheumatic diseases and malignant diseases sometimes occur in the same patient, either sequentially or simultaneously. This can be by coincidence, but it is also established that many of the systemic inflammatory diseases, such as rheumatoid arthritis (RA), Sjögren syndrome, or systemic lupus erythematosus, per se increase the risk of malignant disease. Nevertheless, when rheumatic and malignant diseases occur in the same patient, this usually

*Correspondence: daniel.aletaha@meduniwien.ac.at

2Division of Rheumatology, Department of Internal Medicine 3, Medical University Vienna, Waehringer Guertel 18-20, 1090 Vienna, Austria

Full list of author information is available at the end of the article poses a therapeutic challenge to either the rheumatologist or the oncologist, depending on which of the two problems dominates in a given patient. In this review, we want to address the specific situation of a patient who has cancer or a history of cancer and who presents to the rheumatologist with a severe rheumatic condition that requires immunomodulation or immunosuppression.

The initial question of the possible temporal and causal associations that possibly lead to this clinical situation arises. In principal, a healthy individual can develop a malignancy and subsequently a rheumatic disease simply by natural causes (Figure 1, arrow 1). Potentially, the treatment of the malignant disease may cause the rheumatic complaints (Figure 1, arrow 5) and, in theory, could also support the treatment of the rheumatic condition (Figure 1, arrow 6).

Is it safe to use immunosuppressive drugs to treat a rheumatic patient with a (past) malignancy? At least some concern arises from the fact (or myth?) that some of these drugs have a potential to induce or promote a malignant disease (Figure 1, arrow 3). In the literature, however, this issue is very difficult to assess and is always overshadowed by the fact that some of the rheumatic entities have a per se increased risk for developing a malignant disease (Figure 1, arrow 2). Potentially, antirheumatic treatment may also serve to control a malignant disease (for example, rituximab may be used to treat lymphoma) (Figure 1, arrow 4). There is a large body of literature exploring the risk of malignancy in treated or untreated RA. The main purpose of this review, however, is to summarize the evidence that may help resolve the clinically problematic scenario of immunosuppressive therapy for rheumatic patients with a history of cancer. The logical clinical outcome to evaluate for this purpose is the rate of cancer reactivation. As we will see, the direct evidence is scarce, and we will need to look at neighboring fields, especially the transplantation literature, to further explore the risk of cancer reactivation upon immunosuppressive treatment at a later stage.

For the sake of simplicity, we wish to exclude antiinflammatory drugs and analgesics from our consideration and to focus on RA as the most prevalent inflammatory rheumatic condition. However, before looking at the respective direct and indirect evidence, we must understand the risk of cancer per se (that is, in 


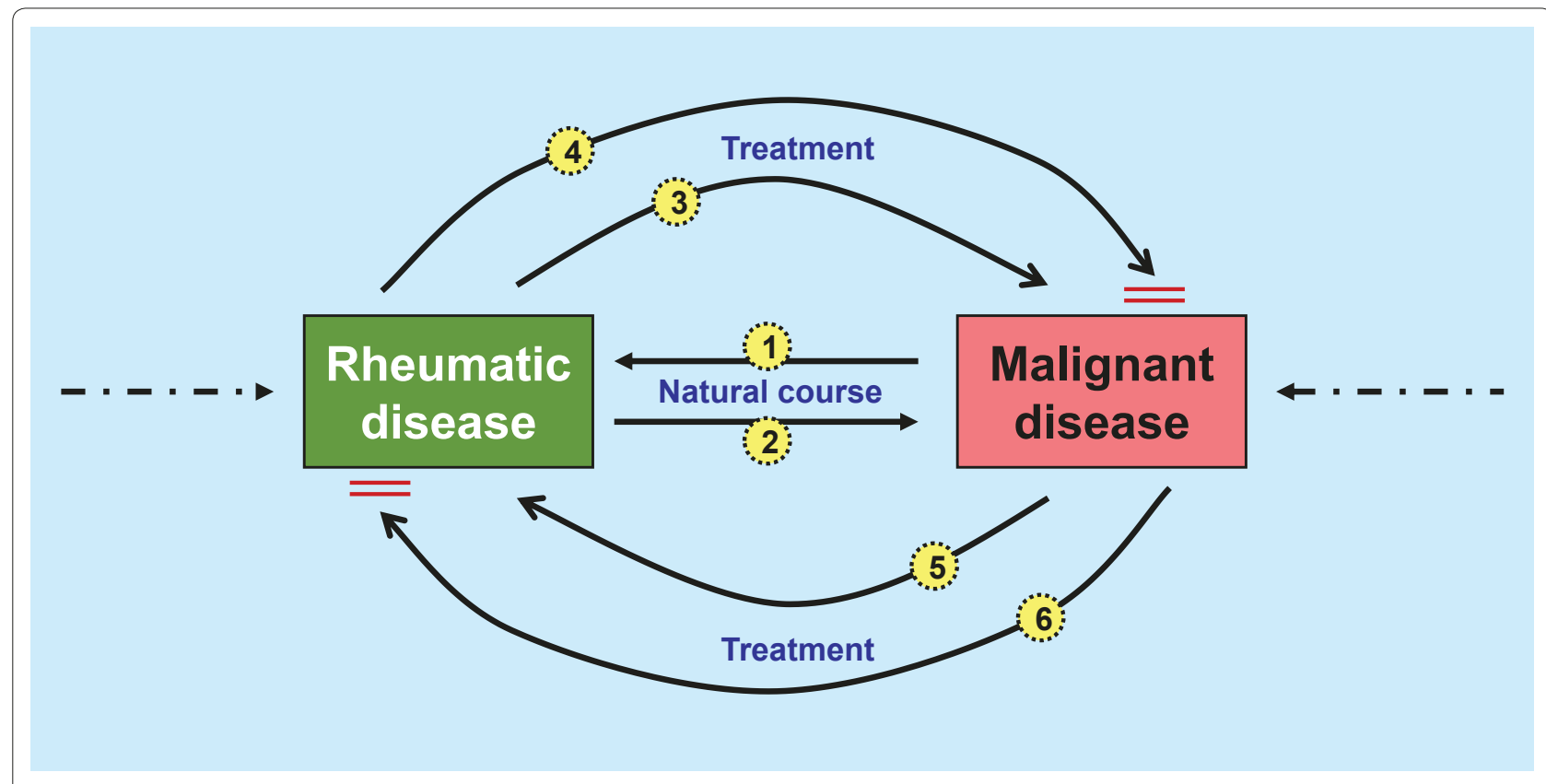

Figure 1. Temporal and causal associations between rheumatic and malignant diseases. A detailed description is presented in the 'Defining the problem'section.

patients with RA but without a history of cancer) with the different drugs used.

\section{Immunosuppressive therapy and the development of malignancies in patients without prior malignancy}

Carcinogenesis and lymphomagenesis are complex processes involving genetic modulation and deregulation of the inflammatory response, causing a resistance to apoptosis, unrestricted proliferation, increased angiogenesis, eventual invasion of blood and lymphatic vessels, and metastasis. In the past, immunosuppressive drugs have been blamed for promoting these processes by leading to a general downregulation of the immune system (impairment of tumor surveillance) or increasing the susceptibility to infection with oncogenic agents. For some others, specific mechanisms (for example, the direct pharmacologic alteration of DNA) have led to these concerns.

Aside from these general concepts of tumorigenesis, the question of whether (and to what extent) there are differences in the risk of malignancy following different drugs arises. In the following, we will briefly mention each of the relevant regimens. Figure 2 gives an overview of the semiquantitative assessment of the cancer risk of specific drugs on the basis of the literature. These risks of malignancy in patients without a tumor might be an initial point of consideration and give some guidance when planning to treat a patient with (a history of) a malignant disease.

\section{Glucocorticoids}

The pleiotropic immunosuppressive effects of glucocorticoids are the basis for the assumption that their use may promote immune-related cancers. Most of the commonly found associations of malignancies with (dosage and duration of) glucocorticoid treatment relate to basal cell carcinoma, squamous cell carcinoma, non-Hodgkin lymphoma, and malignant melanoma [1-3].

On the other hand, some studies have questioned whether these associations were causal $[4,5]$. In the context of rheumatic diseases, it therefore remains entirely unclear whether a significant risk of cancer is related to the underlying systemic disease, other immunosuppressive agents, and their combination or to the glucocorticoids per se. Nevertheless, the discordance of data in the literature might indicate that glucocorticoids at least do not carry a very high risk of malignancy and that they might be relatively safe regarding solid organ tumors, especially if used in reasonable doses and for limited periods of time.

\section{Methotrexate}

Methotrexate is one of the most important antirheumatic regimens and has the least evidence regarding a potentially increased malignancy risk. This has been demonstrated in cohorts with a variety of diseases. For incident cancers, it is again not clear whether this reflects the disease per se or the treatment with methotrexate, which is often used to treat persistent active 


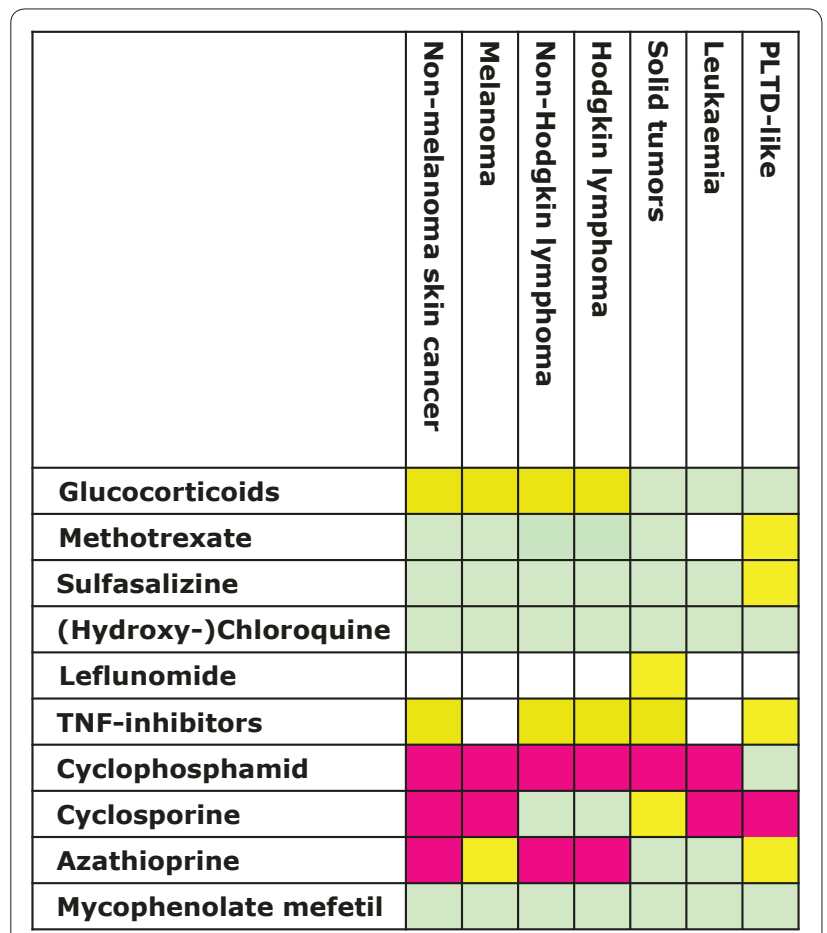

Figure 2. Semiquantitative assessment of malignancy risk associated with specific drugs. Red boxes indicate evidence for increased risk, yellow boxes indicate potential risk, and green boxes indicate little risk; blank boxes indicate that evidence is currently insufficient to determine risk. PLTD-like, post-transplant lymphoproliferative disorder-like; TNF, tumor necrosis factor.

inflammatory disease, such as RA or myositis. However, in some cases, cancer was reversible after the discontinuation of methotrexate. There are reports of an increased risk of a post-transplant lymphoproliferative disorder-like (PTLD-like) condition in patients treated with methotrexate [6,7].

Other traditional disease-modifying anti-rheumatic drugs Other traditional disease-modifying anti-rheumatic drugs (DMARDs) include sulfasalazine, (hydroxy-)chloroquine, and leflunomide. Sulfasalazine has even been postulated as chemo-prevention of colorectal cancer in patients with colitis ulcerosa [8]. On several cell lines, sulfasalazine has also shown anti-tumor activity in vitro [9], but a clinically relevant effect in vivo has not yet been shown. Available data regarding the carcinogenetic potential of chloroquine and hydroxychloroquine are limited and include a long-term observation in rats, in which no evidence of an association with cancer could be established. For leflunomide, explicit human data are currently not available, but animal studies, such as those in rats, also detected no carcinogenetic potential.

\section{Biologics}

Biologics are a novel substance group with wide use in rheumatic and inflammatory diseases. They interfere with cytokine signaling through various interactions with the cytokines and their receptors. A meta-analysis of 5,014 patients of randomized controlled clinical trials in RA has found an increased risk of malignancy with monoclonal antibody tumor necrosis factor (TNF) inhibitors (while etanercept was excluded from their analysis) (odds ratio (OR) 2.4, 95\% confidence interval (CI) 1.2 to 4.8) [10] but has been questioned by many for various design and analysis issues. Also, this study contradicts seven large observational studies of thousands of RA patients followed for a long time; those studies all found no increased overall cancer risk with anti-TNF agents. Askling and colleagues [11] reported a decreased relative risk of colorectal $(-25 \%)$ and breast $(-20 \%)$ cancer in patients with RA treated with TNF blockers. One of the studies, by Wolfe and Michaud [12], observed a higher risk for non-melanoma skin cancer (OR 1.5, 95\% CI 1.2 to 1.8). Data from the Crohn disease cohort also found no increased risk of malignancy with TNF inhibitors (OR 1.33, 95\% CI 0.46 to 3.84). Nevertheless, TNF inhibitors may accelerate the diagnosis of cancer in the first 6 to 12 months of treatment but probably do not increase long-term cancer risk [10-26]. A potentially severe interaction between alkylating drugs and TNF inhibitors was revealed in a randomized, controlled trial in which etanercept versus placebo in addition to conventional therapy for Wegener granulomatosis was evaluated and in which an excess occurrence of solid tumors was observed (standardized incidence ratio $3.12,95 \%$ CI 1.15 to 6.80 ) [14].

In these large-scale long-term data on the use of TNF inhibitors from different registries, the risk of induction of a malignant disease by these drugs appears to be relatively low though still controversial. The lack of clearly consistent findings, however, might also be an indicator that such a risk, if it exists, will likely be low and of questionable clinical relevance. There are currently too few data to investigate newer TNF inhibitors, such as golimumab and certolizumab, or biologics with other modes of action, such as abatacept and tocilizumab. Rituximab, a monoclonal antibody against anti-CD20, is itself used in treatment for malignant lymphoma and PTLD. Little is known about its risk of secondary malignancies in patients with RA.

\section{Alkylating agents}

In rheumatology, this group of immunosuppressants, the classical 'chemotherapies', is reserved for treatment of patients with severe organ involvement, usually of connective tissue disease or vasculitis. Alkylating agents increase the risk of hematologic malignancy, and 
cyclophosphamide, in particular, increases the incidence of bladder cancer [27-30]. The increased risk of malignancy under cyclophosphamide therapy may not be evident until several years after treatment (5\% at 10 years and $16 \%$ at 15 years) [30]. Little evidence exists for chlorambucil, even in the transplantation literature. Similarly to cyclophosphamide, it has been associated with a substantially higher rate of secondary hematologic neoplasm (in patients treated for malignancies), and leukemia may even be seen more frequently than with cyclophosphamide [31]. In addition, a small study of chlorambucil in RA found that $21 \%$ of patients developed cutaneous neoplasia (mostly squamous cell carcinoma).

In summary, alkylating agents increase the risk of secondary hematologic malignancies, but as high-pulse doses of alkylating agents are used for treatment of hematologic malignancies, they might occasionally even serve the treatment of both conditions in a single patient. A broad spectrum of malignancies, such as might be expected if induction of mutation were the prevailing oncogenic mechanism, was not described for these agents [30], but caution needs to be taken in patients with a history of skin cancer or urogenital cancer (when cyclophosphamide is considered).

\section{Calcineurin inhibitors}

Cyclosporine and tacrolimus are less frequently used for the treatment of rheumatic diseases in the recent past but do not seem to increase cancer risk to a detectable degree in patients with an inflammatory disease such as RA [32]. However, appreciation of the transplant literature calls for caution if these drugs are used in combination with glucocorticoids or other immunosuppressants (or both) in patients with a malignant disease or a history of one, although the role of cyclosporine itself remains unclear [32-37].

\section{Anti-metabolites}

Anti-metabolites, such as azathioprine, showed no significant increase in the risk of cancer development in patients with inflammatory disease [38-41]. A case control study in multiple sclerosis patients with and without cancer found no association with azathioprine exposure [40]. In contrast, transplant patients treated with azathioprine, compared with the general population, probably do have an increased risk of malignancy, including squamous cell carcinoma of the skin and lymphoid malignancies (Hodgkin and non-Hodgkin lymphoma) $[42,43]$. Again, the combination immunosuppressive therapy makes it difficult to assess true causality.

\section{Mycophenolate mofetil}

Mycophenolate mofetil is one of the newer drugs typically used in transplantation. Observational trials of mycophenolate have found a significantly and substantially reduced risk of PTLDs, a lower risk of malignancy in general, and an improvement of survival in this patient population in comparison with alternative drugs, like azathioprine, cyclosporine, tacrolimus, or their combinations [42-47].

\section{Rapamycin}

Though not used to treat rheumatologic disorders, rapamycin (inhibitor of mammalian target of rapamycin, or mTOR) is worth noting in this review. It is an immunosuppressive agent with anti-oncogenic properties and therefore might be an immunosuppressive treatment option to be considered and investigated for patients who have rheumatic disorders and who are at risk for or have a history of cancer [48-50].

\section{Direct evidence on the risk of immunosuppressive therapy of patients with current or past malignancy \\ Data from the field of rheumatology}

The very topic of this review is the safety of immunosuppressants in rheumatic patients who have a history of malignant disease. To identify evidence in this field, we performed a literature search of Medline, Embase, and the Cochrane database by using terms that define the various inflammatory rheumatic diseases and combining these with the term 'malignancy' and its synonyms. In total, two studies investigated the risk of cancer recurrence in rheumatic patients; all others were addressing either the risk of cancer associated with the respective rheumatic condition or its treatment in patients without a history of cancer (or both).

The first study, a prospective observational study using data from the British Society for Rheumatology Biologics Register, identified 293 patients with prior malignancy from more than 14,000 patients with RA [51]. Prior nonmelanoma skin cancers were excluded. The overall cancer incidence in this population was evaluated in patients who were then exposed to TNF inhibitors $(n=177)$ or traditional DMARDs $(n=117)$. In summary, the rate of incident malignancy was numerically even lower in the TNF inhibitor group, but selection bias needs to be considered (patients with a high risk of relapse are more likely to be treated with traditional DMARDs). Only one patient developed a local recurrence; all other tumors were de novo. Interestingly, among patients with prior melanoma, 3 out of 17 in the TNF inhibitor group developed an incident malignancy (of any kind) whereas 0 out of 10 in the DMARD group did so.

The second study was similarly based on a national register, the German RABBIT (German acronym for Rheumatoid Arthritis - Observation of Biologic Therapy) register, in which 122 patients with a prior malignancy 
had been identified from a total of 5,120 patients. The 122 patients showed no significant increase in the risk of relapse on TNF inhibitor therapy compared with conventional DMARD therapy [52]. Interestingly, in contrast to the British study, 14 of the 15 recurrent cancers were of the same type and site as the prior tumor. The authors did not find any signal toward an increased risk of recurrence on TNF inhibitor treatment compared with traditional DMARDs; but, again, the results of this study were limited by the small number of events.

In summary, these two articles on the exact topic of this review were published very recently. They are both observational, based on registry data, and therefore not randomized. The two major problems of these studies are selection bias and low incidence of the outcomes: in the British register, the time since malignancy was far longer in those patients treated with anti-TNF than in the control group and in total longer than in the German register. A considerable proportion of the German patients (equally in the anti-TNF and the control groups) was treated within a time window during which recurrences have to be expected. Nevertheless, the design of these studies is potentially the best direct evidence one can get on the question posed here. Additional and more extensive data will need to be borrowed from other fields, mostly from the field of solid organ transplantation.

\section{Data from the field of solid organ transplantation}

When data are borrowed from the field of transplantation, the main limitation is that, given the combination treatment of immunosuppressants, it is usually very difficult to determine which specific drug (if any) is responsible for cancer recurrence. This very intensive immunosuppression, in combination with the absence of an underlying autoimmune disease, makes the translation of transplant data to the rheumatologic field very difficult. Aware of these limitations, we will briefly look at the major findings from these studies and general conclusions that might be drawn for rheumatic patients.

A relapse rate of $21 \%$ was reported in a retrospective analysis of 1,137 malignancy patients who received a renal graft [53]. In regard to cancer type, the highest recurrence rates occurred with multiple myeloma (67\%), non-melanoma skin cancers (53\%), sarcomas (29\%), bladder cancer (29\%), symptomatic renal tumors (27\%), and breast cancer $(23 \%)$. In regard to timing of immunosuppression, most recurrences (35\%) were seen in patients who were treated for a malignant disease within 2 years prior to transplantation. In those treated 2 to 5 years or more than 5 years before transplantation, 33\% and $13 \%$ relapses were diagnosed, respectively (Figure 3 ).

In a study of 939 patients treated for cancer prior to transplantation, 185 (22\%) showed cancer recurrence, and $53 \%$ of relapses occurred in patients treated within
2 years before transplantation [54]. Table 1 gives an overview of which cancers had shown a low, an intermediate, or a high risk of relapse.

Current guidelines for the clinical management of transplant patients indicate a prompt reduction or discontinuation of immunosuppressive drugs once the posttransplant malignancy is diagnosed [55-59]. The obvious downside is that such a strategy may precipitate allograft rejection and graft failure. The higher incidence of relapses following immunosuppression therefore has led to the recommendation of a 2-year waiting period between (successful) cancer treatment and organ transplantation [53,54,60-62]. Nevertheless, the 2-year waiting period might be justified for most malignancies, whereas for carcinoma in situ, low-grade bladder, and basal cell skin tumors, no waiting period is necessary. On the other hand, longer waiting periods (of over 24 months) are needed for other malignancies, such as melanoma, breast cancer, and colorectal cancer. For lymphomas, a waiting period of approximately 5 years is desirable [53,54,60-62].

\section{Risk stratification of considerations}

\section{Type and prognosis of malignancy}

According to the World Health Organization definition, tumors can be categorized regarding their potential curability into five categories; examples for each are given in Table 1. This system can be an initial guidance for evaluation of the malignant potential of the cancer that has been treated, although these categories only roughly reflect prognosis. The EUROCARE-4 (European Cancer Registry-Based Study on Survival and Care of Cancer Patients) Working Group published mean age-adjusted 5-year survival data for patients whose cancer was diagnosed between 2000 and 2002 [63]; the results are also shown in Table 1.

\section{Quality of cancer care}

In general, the survival of patients depends on many additional aspects that are not considered if only survival rates are presented. The quality of care - as reflected in effective programs on prevention and screening, access to diagnostic and treatment facilities, tumor-site-specific protocols, multidisciplinary management, application of evidence-based clinical guidelines, and recruitment to clinical trials - considerably influences the outcome and survival of patients with cancer. This may explain, in part, the considerable regional differences that can be noted in cancer survival, but differences in populations also likely play a role here $[63,64]$.

\section{Burden of disease and remission of malignancy}

Regardless of the type and prognosis of a tumor, assessments of the current stage of tumor burden (presence of remission) or its change (response) have to be evaluated. 


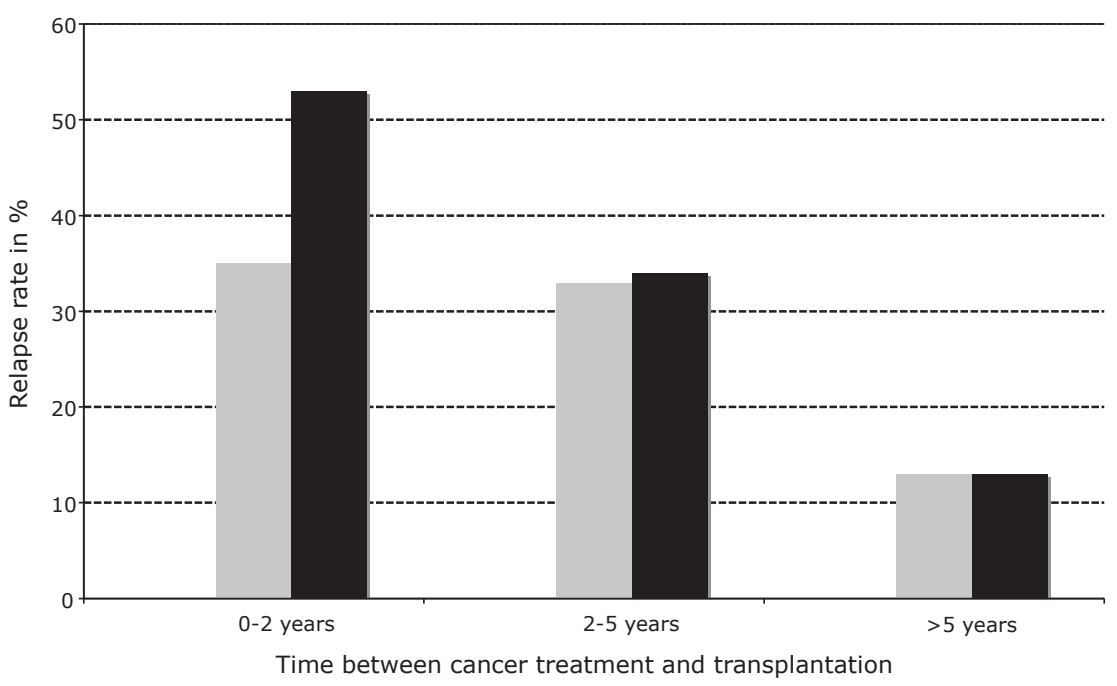

Figure 3. Risk of cancer relapse from solid organ transplantation according to time between cancer treatment and transplantation (adapted from Penn, 1993, black bars [54] and Penn, 1997, gray bars [53]). The data from 1997, with longer follow-up period and higher patient number, lead to the recommendation of longer waiting time between tumor treatment and transplantation in graft recipients with preexisting malignancies.

A very important aspect is the issue of when to consider a malignant disease in remission; conceptually, this would be the earliest time point at which a patient with a history of cancer could reasonably safely be treated with an immunosuppressive drug. The term 'remission' implies that the disease has been either eliminated or substantially reduced. The RECIST (Response Evaluation Criteria In Solid Tumors) criteria, a classification system that was published in 2009, may be used for that purpose [65]. The evaluation of response status is performed at the end of a treatment period and includes results from clinical examination, imaging techniques, and specific lab tests. The RECIST system defines complete remission, partial remission, stable disease, and progressive disease. Given the lack of evidence on the risk of cancer relapse by stage, a complete remission seems to be a reasonable prerequisite before the initialization of immunosuppressive treatment is considered. For accurate classification according to the RECIST system, consultation with an oncologist would be useful.

\section{Special clinical situations}

Rheumatic conditions as a consequence of cancer therapy There is evidence that chemotherapy for malignant diseases may induce rheumatic diseases [66-70] (Figure 1, arrow 5); in such a case, the primary treatment would be the discontinuation of the culprit agent if this is possible. However, it is conceivable that classical anti-rheumatic treatment approaches may also need to be considered in some of these patients; in that case, all considerations made so far would apply.

\section{Post-transplant lymphoproliferative disorder}

PTLD covers a disease spectrum ranging from infectious mononucleosis to malignant lymphoma, and although by definition PLTD occurs in transplant patients, the likely cause is the combined immunosuppressive treatment rather than the fact that an organ has been transplanted. Early polymorphic lymphomas, which are Epstein-Barr virus (EBV)-positive, respond well to the reduction of immunosuppression. In contrast, EBV-negative, monomorphic types are unresponsive to the reduction of immunosuppression and have a poorer prognosis. As many of the rheumatic conditions per se put patients at risk for lymphoproliferative disease, this might even be the case when there is no history of malignant disease.

\section{Suggested management}

A challenge faced in this review is the lack of direct evidence that could be used to advise physicians on how to proceed in the clinical situation of a cancer patient with a rheumatic condition requiring immunosuppressive treatment. Thus, only circumstantial evidence can be used to infer a strategic approach. This includes data on the frequency of new-onset malignancy, the potential treatments that may be used, data on the malignant potential of different tumors, and (of course) data from other fields in which immunosuppressive agents are employed more commonly and in which similar clinical questions have been raised.

On the basis of these data, a very generic stepwise approach to the problem can be taken as suggested in Figure 4. The first step obviously is to recognize the 
Table 1. Survival and characteristics of cancer

\begin{tabular}{|c|c|c|c|c|}
\hline Tumor site & $\begin{array}{c}\text { European average } \\
\text { 5-year survival }[63,64]\end{array}$ & $\begin{array}{l}\text { Tumor category } \\
\text { (WHO) })^{\mathrm{a}}\end{array}$ & $\begin{array}{c}\text { Risk of relapse }^{b} \\
{[53,54,59-61]}\end{array}$ & $\begin{array}{c}\text { Recurrence rate after } \\
\text { transplantation }[53,54,59-61]\end{array}$ \\
\hline Pancreas & $5.7 \%$ & 5 & - & - \\
\hline Liver & $9.1 \%$ & 2 & - & - \\
\hline Esophagus & $11.1 \%$ & 3 & - & - \\
\hline Lung & $12.0 \%$ & 3 & - & - \\
\hline Gallbladder and biliary tract & $14.4 \%$ & 5 & - & - \\
\hline Brain & $19.7 \%$ & & - & - \\
\hline Stomach & $24.5 \%$ & 3 & - & - \\
\hline Multiple myeloma & $35.1 \%$ & & +++ & $>25 \%$ \\
\hline Ovary and uterine adnexa & $36.5 \%$ & 2 & - & - \\
\hline Head and neck & $39.5 \%$ & 3 & - & - \\
\hline All leukemias & $42.4 \%$ & 1 and 3 & - & - \\
\hline $\mathrm{NHL}$ & $51.5 \%$ & 1 & + & Up to $10 \%$ \\
\hline Colorectal & $54.0 \%$ & 2 & ++ & $11 \%-25 \%$ \\
\hline Bone and cartilage & $55.5 \%$ & 3 & +++ & $>25 \%$ \\
\hline Kidney & $58.0 \%$ & & +++ & $>25 \%$ \\
\hline Soft tissue sarcoma & $59.5 \%$ & 2 & +++ & $>25 \%$ \\
\hline Cervix uteri & $62.6 \%$ & 3 & + & Up to $10 \%$ \\
\hline Bladder & $72.4 \%$ & 3 & +++ & $>25 \%$ \\
\hline Larynx & $62.8 \%$ & 4 & & \\
\hline Corpus uteri & $76.2 \%$ & 3 & ++ & $11 \%-25 \%$ \\
\hline Prostate & $76.4 \%$ & 3 & ++ & $11 \%-25 \%$ \\
\hline Breast & $79.4 \%$ & 2 & ++ & $11 \%-25 \%$ \\
\hline Hodgkin & $80.1 \%$ & 1 & + & Up to $10 \%$ \\
\hline Melanoma of skin & $82.6 \%$ & 5 & +++ & $>25 \%$ \\
\hline Thyroid & $82.9 \%$ & 5 & + & Up to $10 \%$ \\
\hline Testis & $89.5 \%$ & 1 & + & Up to $10 \%$ \\
\hline
\end{tabular}

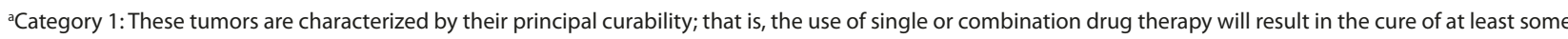
patients. Category 2: For these cancers, the survival is prolonged when adjuvant chemotherapy is used with surgery or radiotherapy in the early stages. Category 3 : These are neoplasms, for which there is evidence that the use of a single drug or combination of drugs will cause tumor shrinkage and possibly improve quality of life; survival may be prolonged but this may be of short duration. Category 4: The local control of these malignancies may be improved by the use of chemotherapy

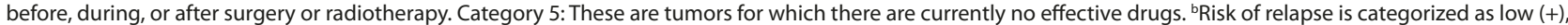
intermediate (++), or high (+++). NHL, non-Hodgkin lymphoma; WHO, World Health Organization.

problem (that is, to take a detailed history regarding malignant diseases in the past in every patient considered for immunosuppressive therapy). In case of a currently active/ongoing malignancy, it should be considered whether the rheumatic disease to be treated is of paraneoplastic or tumor-associated pathogenesis, in which case the treatment of the malignancy is the first therapeutic step. Alternatively, a therapeutic regimen that has been used for treatment of the malignant disease may be the cause of the rheumatic complaints; in that case, discontinuation and change of regimen would be the optimal approach. Of note, some of the chemotherapy-related rheumatic disorders may not appear until as much as 1 year after cytotoxic therapy. However, these conditions, if not related to neoplasm relapse, usually disappear without additional therapy.

If neither the ongoing malignancy nor its treatment can be attributed as the cause of the rheumatic condition (that is, the rheumatic and oncologic diseases are independent), a consultation with an oncologist will be required before any immunosuppressive/DMARD treatment can be employed. It is likely that the patient will be considered ineligible for such treatment and that only symptomatic therapy can be used.

In case of the absence of an active malignant disease but a positive history of such a disease, the prevailing disease status needs to be evaluated. As the initial step here, the 


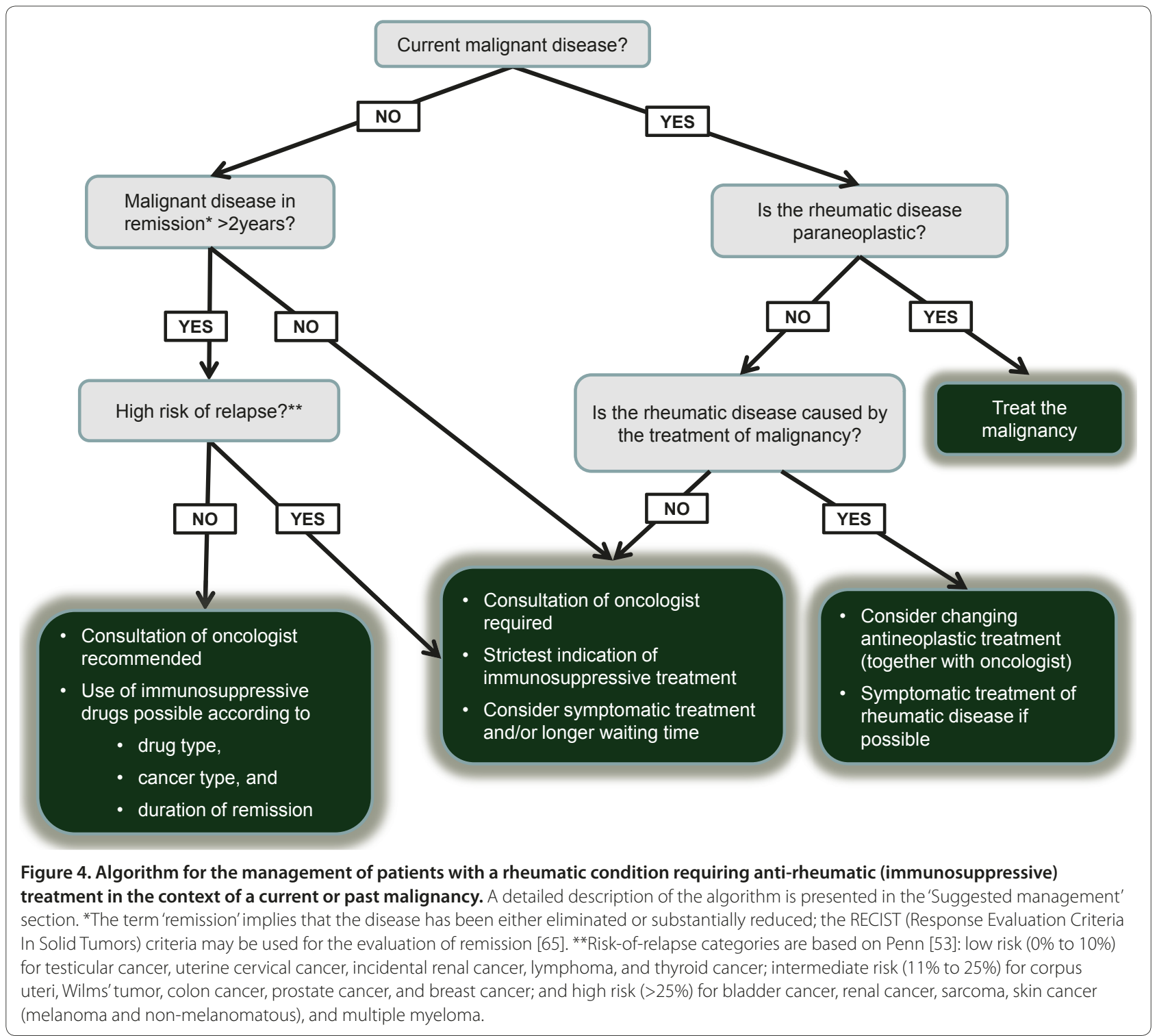

task is to determine the duration of complete remission (that is, the recovery from all evidence of disease). On the basis of the transplant literature and the scarce data from registries on rheumatic diseases, 2 years seem to be the minimum requirement for cancers with low to intermediate risk of relapse, whereas those with a high risk of relapse should likely be handled similarly to patients with an active/ongoing malignant disease (Figure 4).

Once the decision of using an immunosuppressive agent is an option in a given patient, the choice of drug is the next decision to be made. This decision will be a combined evaluation of the risk of relapse on the basis of the cancer type and the length of remission as well as the tumorigenic potential of the drug to be used (as briefly reviewed above). An interdisciplinary conference with an experienced oncologist is still advisable.
Especially when considering data from the transplantation literature, however, the fact that usually a combination therapy of multiple drugs is employed should be considered before risks are attributed to individual drugs. For example, it remains unclear whether monotherapy of glucocorticoids, calcineurin inhibitors, or anti-metabolites are afflicted with an increased cancer risk. In fact, outside the transplantation literature, there is no solid evidence for such a risk after exposure to each of these regimens individually. Exceptions to this are likely the alkylating agents, which seem to increase hematologic malignancy risk, and (in particular) cyclophosphamide, which increases the incidence of bladder cancer. In any case, it needs to be emphasized again that the direct evidence investigating the risk of anti-rheumatic treatment in patients with a history of malignancy is sparse. 
The most commonly 'required' anti-rheumatic treatments, however, are methotrexate and probably the biological response modifiers, especially the TNF inhibitors. In regard to the risk of malignancy following methotrexate, the literature is very favorable, demonstrating a low lymphoma incidence in almost a million exposed patients, although some cases of PTLD-like syndrome were seen. For this reason, methotrexate seems to be a drug with a safe profile. Similarly, TNF inhibitors have a very favorable risk profile in regard to cancer development on the basis of exposure of thousands of patients with RA, although TNF inhibitors may accelerate the diagnosis of cancer in the first 6 to 12 months of treatment. According to some reports, TNF inhibitors may even decrease the risk of colorectal and breast cancer in patients with RA. However, on the basis of the available literature, it would be advisable to be cautious with combined immunosuppressive treatment in patients with a history of cancer.

In selected cases, less commonly used drugs, given their relatively good data indicating even lower cancer rates, may be used in patients with a history of cancer. These include mycophenolate mofetil, which has shown a significant and substantial risk reduction of PTLD-like disorder as well as a lower risk of malignancy in general. The mTOR inhibitors, with their impressive anti-oncogenic properties, may be considered to be alternative immunosuppressives in special clinical situations.

\section{Conclusions}

In summary, if patients with a history of cancer are exposed to immunosuppressive drugs, regular and frequent monitoring is certainly an essential requirement. This may include the use of relevant tumor markers or more frequent staging examinations. After all of the considerations about the risk of cancer recurrence and the tumorigenic potential of the drug to be employed, one important aspect should not be overlooked, namely the potential undertreatment of the rheumatic condition, which might lead to a reduction in quality of life or, potentially even more than the underlying malignant disease in some instances, might be a threat to life itself.

This article is part of the series Comorbid conditions in subjects with rheumatic diseases, edited by Daniel Aletaha and Thomas Dörner. Other articles in this series can be found at http://arthritis-research.com/series/comorbid

\section{Abbreviations}

$\mathrm{Cl}$, confidence interval; DMARD, disease-modifying anti-rheumatic drug; EBV Epstein-Barr virus; mTOR, mammalian target of rapamycin; OR, odds ratio; PTLD, post-transplant lymphoproliferative disorder; RA, rheumatoid arthritis; RECIST, Response Evaluation Criteria In Solid Tumors; TNF, tumor necrosis factor.

\section{Competing interests}

The authors declare that they have no competing interests.

\section{Author details}

'Division of Oncology, Department of Internal Medicine 1, Medical University Vienna, Austria. ${ }^{2}$ Division of Rheumatology, Department of Internal Medicine 3, Medical University Vienna, Waehringer Guertel 18-20, 1090 Vienna, Austria.

Published: 29 June 2011

\section{References}

1. Sorensen HT, Mellemkjaer L, Nielsen GL, Baron JA, Olsen JH, Karagas MR: Skin cancers and non-Hodgkin lymphoma among users of systemic glucocorticoids: a population-based cohort study. J Nat/ Cancer Inst 2004, 96:709-711.

2. Karagas MR, Cushing GL Jr., Greenberg ER, Mott LA, Spencer SK, Nierenberg DW: Non-melanoma skin cancers and glucocorticoid therapy. Br J Cancer 2001, 85:683-686.

3. Jensen $A \varnothing$, Thomsen HF, Engebjerg MC, Olesen AB, Friis S, Karagas MR, Sørensen HT: Use of oral glucocorticoids and risk of skin cancer and nonHodgkin's lymphoma: a population-based case-control study. Br J Cancer 2009, 100:200-205.

4. Askling J, Klareskog L, Hjalgrim H, Baecklund E, Bjorkholm M, Ekbom A: Do steroids increase lymphoma risk? A case-control study of lymphoma risk in polymyalgia rheumatica/giant cell arteritis. Ann Rheum Dis 2005, 64:1765-1768.

5. Baecklund E, Iliadou A, Askling J, Ekbom A, Backlin C, Granath F, Catrina Al, Rosenquist R, Feltelius N, Sundstrom C, Klareskog L: Association of chronic inflammation, not its treatment, with increased lymphoma risk in rheumatoid arthritis. Arthritis Rheum 2006, 54:692-701.

6. Alarcon GS, Tracy IC, Strand GM, Singh K, Macaluso M: Survival and drug discontinuation analyses in a large cohort of methotrexate treated rheumatoid arthritis patients. Ann Rheum Dis 1995, 54:708-712.

7. Wolfe F, Michaud $K$ : The effect of methotrexate and anti-tumor necrosis factor therapy on the risk of lymphoma in rheumatoid arthritis in 19,562 patients during 89,710 person-years of observation. Arthritis Rheum 2007, 56:1433-1439.

8. Chan EP, Lichtenstein GR: Chemoprevention: risk reduction with medical therapy of inflammatory bowel disease. Gastroenterol Clin North Am 2006, 35:675-712.

9. Weber CK, Liptay S, Wirth T, Adler G, Schmid RM: Suppression of NK-kappaB activity by sulfasalazine is mediated by direct inhibition of IkappaB kinase alpha and beta. Gastroenterology 2000, 119:1209-1218.

10. Bongartz T, Sutton AJ, Sweeting MJ, Buchan I, Matteson EL, Montori V: AntiTNF antibody therapy in rheumatoid arthritis and the risk of serious infections and malignancies: systematic review and meta-analysis of rare harmful effects in randomized controlled trials. JAMA 2006, 295:2275-2285.

11. Askling J, Fored CM, Brandt L, Baecklund E, Bertilsson L, Feltelius N, Coster L, Geborek P, Jacobsson LT, Lindblad S, Lysholm J, Rantapaa-Dahlqvist S, Saxne T, Klareskog L: Risks of solid cancers in patients with rheumatoid arthritis and after treatment with tumour necrosis factor antagonists. Ann Rheum Dis 2005, 64:1421-1426.

12. Wolfe F, Michaud K: Biologic treatment of rheumatoid arthritis and the risk of malignancy: analyses from a large US observational study. Arthritis Rheum 2007, 56:2886-2895.

13. Okada SK, Siegel JN: Risk of serious infections and malignancies with antiTNF antibody therapy in rheumatoid arthritis. JAMA 2006, 296:2201-2202.

14. Stone JH, Holbrook JT, Marriott MA, Tibbs AK, Sejismundo LP, Min YI, Specks U, Merkel PA, Spiera R, Davis JC, St Clair EW, McCune WJ, Ytterberg SR, Allen NB, Hoffman GS: Solid malignancies among patients in the Wegener's Granulomatosis Etanercept Trial. Arthritis Rheum 2006, 54:1608-1618.

15. Setoguchi S, Solomon DH, Weinblatt ME, Katz JN, Avorn J, Glynn RJ, Cook EF, Carney G, Schneeweiss S: Tumor necrosis factor alpha antagonist use and cancer in patients with rheumatoid arthritis. Arthritis Rheum 2006, 54:2757-2764.

16. Fleischmann RM, Tesser J, Schiff MH, Schechtman J, Burmester GR, Bennett $R$, Modafferi D, Zhou L, Bell D, Appleton B: Safety of extended treatment with anakinra in patients with rheumatoid arthritis. Ann Rheum Dis 2006, 65:1006-1012.

17. Lebwohl M, Blum R, Berkowitz E, Kim D, Zitnik R, Osteen C, Wallis WJ: No evidence for increased risk of cutaneous squamous cell carcinoma in patients with rheumatoid arthritis receiving etanercept for up to 5 years. Arch Dermatol 2005, 141:861-864.

18. Jacobsson LT, Turesson C, Nilsson JA, Petersson IF, Lindqvist E, Saxne T, 
Geborek P: Treatment with TNF blockers and mortality risk in patients with rheumatoid arthritis. Ann Rheum Dis 2007, 66:670-675.

19. Askling J, Fored CM, Baecklund E, Brandt L, Backlin C, Ekbom A, Sundstrom C, Bertilsson L, Coster L, Geborek P, Jacobsson LT, Lindblad S, Lysholm J, Rantapaa-Dahlqvist S, Saxne T, Klareskog L, Feltelius N: Haematopoietic malignancies in rheumatoid arthritis: lymphoma risk and characteristics after exposure to tumour necrosis factor antagonists. Ann Rheum Dis 2005, 64:1414-1420.

20. Carmona L, Descalzo MA, Perez-Pampin E, Ruiz-Montesinos D, Erra A, Cobo T, Gomez-Reino JJ: All-cause and cause-specific mortality in rheumatoid arthritis are not greater than expected when treated with tumour necrosis factor antagonists. Ann Rheum Dis 2007, 66:880-885.

21. Geborek P, Bladstrom A, Turesson C, Gulfe A, Petersson IF, Saxne T, Olsson H, Jacobsson LT: Tumour necrosis factor blockers do not increase overall tumour risk in patients with rheumatoid arthritis, but may be associated with an increased risk of lymphomas. Ann Rheum Dis 2005, 64:699-703.

22. Biancone L, Orlando A, Kohn A, Colombo E, Sostegni R, Angelucci E, Rizzello F, Castiglione F, Benazzato L, Papi C, Meucci G, Riegler G, Petruzziello C, Mocciaro F, Geremia A, Calabrese E, Cottone M, Pallone F: Infliximab and newly diagnosed neoplasia in Crohn's disease: a multicentre matched pair study. Gut 2006, 55:228-233.

23. Waldmann TA: Daclizumab (anti-Tac, Zenapax) in the treatment of leukemia/lymphoma. Oncogene 2007, 26:3699-3703.

24. Lane L, Tamesis R, Rodriguez A, Christen W, Akova YA, Messmer E, PedrozaSeres M, Barney N, Foster CS: Systemic immunosuppressive therapy and the occurrence of malignancy in patients with ocular inflammatory disease. Ophthalmology 1995, 102:1530-1535.

25. Beauparlant $P$, Papp K, Haraoui B: The incidence of cancer associated with the treatment of rheumatoid arthritis. Semin Arthritis Rheum 1999 29:148-158

26. Wolfe F, Michaud K: Lymphoma in rheumatoid arthritis: the effect of methotrexate and anti-tumor necrosis factor therapy in 18,572 patients. Arthritis Rheum 2004, 50:1740-1751.

27. Pedersen-Bjergaard J, Ersboll J, Hansen VL, Sorensen BL, Christoffersen K Hou-Jensen K, Nissen NI, Knudsen JB, Hansen MM: Carcinoma of the urinary bladder after treatment with cyclophosphamide for non-Hodgkin's lymphoma. NEng/ J Med 1988, 318:1028-1032.

28. Radis CD, Kahl LE, Baker GL, Wasko MC, Cash JM, Gallatin A, Stolzer BL, Agarwal AK, Medsger TA Jr., Kwoh CK: Effects of cyclophosphamide on the development of malignancy and on long-term survival of patients with rheumatoid arthritis. A 20-year followup study. Arthritis Rheum 1995, 38:1120-1127.

29. Hoffman GS, Kerr GS, Leavitt RY, Hallahan CW, Lebovics RS, Travis WD, Rottem M, Fauci AS: Wegener granulomatosis: an analysis of 158 patients. Ann Intern Med 1992, 116:488-498.

30. Talar-Williams C, Hijazi YM, Walther MM, Linehan WM, Hallahan CW, Lubensky I, Kerr GS, Hoffman GS, Fauci AS, Sneller MC: Cyclophosphamide-induced cystitis and bladder cancer in patients with Wegener granulomatosis. Ann Intern Med 1996, 124:477-484.

31. Patapanian H, Graham S, Sambrook PN, Browne CD, Champion GD, Cohen $\mathrm{ML}$, Day RO: The oncogenicity of chlorambucil in rheumatoid arthritis. Br J Rheumatol 1988, 27:44-47.

32. van den Borne $B E$, Landewe $R B$, Houkes I: No increased risk of malignancies and mortality in cyclosporin A-treated patients with rheumatoid arthritis. Arthritis Rheum 1998, 41:1930-1937.

33. Dantal J, Hourmant M, Cantarovich D, Giral M, Blancho G, Dreno B, Soulillou JP: Effect of long-term immunosuppression in kidney-graft recipients on cancer incidence: randomised comparison of two cyclosporin regimens. Lancet 1998, 351:623-628.

34. Opelz G, Döhler B: Lymphomas after solid organ transplantation: a collaborative transplant study report. Am J Transplant 2004, 4:222-230.

35. McGeown MG, Douglas JF, Middleton D: One thousand renal transplants at Belfast City Hospital: post-graft neoplasia 1968-1999, comparing azathioprine only with cyclosporin-based regimes in a single centre. Clin Transp/ 2000:193-202.

36. Caillard S, Dharnidharka V, Agodoa L, Bohen E, Abbott K: Posttransplant lymphoproliferative disorders after renal transplantation in the United States in era of modern immunosuppression. Transplantation 2005, 80:1233-1243

37. Dharnidharka VR, Sullivan EK, Stablein DM, Tejani AH, Harmon WE: Risk factors for posttransplant lymphoproliferative disorder (PTLD) in pediatric kidney transplantation: a report of the North American Pediatric Renal Transplant Cooperative Study (NAPRTCS). Transplantation 2001, 71:1065-1068

38. Fraser AG, Orchard TR, Robinson EM, Jewell DP: Long-term risk of malignancy after treatment of inflammatory bowel disease with azathioprine. Aliment Pharmacol Ther 2002, 16:1225-1232.

39. Kwon JH, Farrell RJ: The risk of lymphoma in the treatment of inflammatory bowel disease with immunosuppressive agents. Crit Rev Oncol Hematol 2005, 56:169-178.

40. Confavreux C, Saddier P, Grimaud J, Moreau T, Adeleine P, Aimard G: Risk of cancer from azathioprine therapy in multiple sclerosis: a case-control study. Neurology 1996, 46:1607-1612.

41. Connell WR, Kamm MA, Dickson M, Balkwill AM, Ritchie JK, Lennard-Jones JE: Long-term neoplasia risk after azathioprine treatment in inflammatory bowel disease. Lancet 1994, 343:1249-1252.

42. David KM, Morris JA, Steffen BJ, Chi-Burris KS, Gotz VP, Gordon RD: Mycophenolate mofetil vs. azathioprine is associated with decreased acute rejection, late acute rejection, and risk for cardiovascular death in renal transplant recipients with pre-transplant diabetes. Clin Transplant 2005, 19:279-285

43. Wang K, Zhang H, Li Y, Wei Q, Li H, Yang Y, Lu Y: Safety of mycophenolate mofetil versus azathioprine in renal transplantation: a systematic review. Transplant Proc 2004, 36:2068-2070.

44. O'Neill JO, Edwards LB, Taylor DO: Mycophenolate mofetil and risk of developing malignancy after orthotopic heart transplantation: analysis of the transplant registry of the International Society for Heart and Lung Transplantation. J Heart Lung Transplant 2006, 25:1186-1191.

45. Engl T, Makarević J, Relja B, Natsheh I, Müller I, Beecken WD, Jonas D, Blaheta RA: Mycophenolate mofetil modulates adhesion receptors of the beta1 integrin family on tumor cells: impact on tumor recurrence and malignancy. BMC Cancer 2005, 5:4

46. Vegso G, Sebestyen A, Paku S, Barna G, Hajdu M, Toth M, Jaray J, Kopper L: Antiproliferative and apoptotic effects of mycophenolic acid in human B-cell non-Hodgkin lymphomas. Leuk Res 2007, 31:1003-1008.

47. Vajdic $C M$, van Leeuwen MT: Cancer incidence and risk factors after solid organ transplantation. Int J Cancer 2009, 125:1747-1754

48. Luan F, Hojo M, Maluccio M, Yamaji K, Suthanthiran M: Rapamycin blocks tumor progression: unlinking immunosuppression from anti-tumor efficacy. Transplantation 2002, 73:1565-1572.

49. Luan FL, Ding R, Sharma VK, Chon WJ, Lagman M, Suthanthiran M: Rapamycin is an effective inhibitor of human renal cancer metastasis. Kidney Int 2003, 63:917-926.

50. Boffa DJ, Luan FL, Thomas D, Yang H, Sharma VK, Lagman M, Suthanthiran M: Rapamycin inhibits the growth and metastatic progression of non-small cell lung cancer. Clin Cancer Res 2004, 10:293-300.

51. Dixon WG, Watson KD, Lunt M, Mercer LK, Hyrich KL, Symmons DP: Influence of anti-tumor necrosis factor therapy on caner incidence in patients with rheumatoid arthritis who had a prior malignancy: results from British Society for Rheumatology Biologics Register. Arthritis Care Res 2010, 62:7255-7263

52. Strangfeld A, Hierse F, Rau R, Burmester GR, Krummel-Lorenz B, Demary W, Listing J, Zink A: Risk of incidence or recurrent malignancies among patients with rheumatoid arthritis exposed to biologic therapy in German biologics register RABBIT. Arthritis Res Ther 2010, 12:R5.

53. Penn I: Evaluation of transplant candidates with pre-existing malignancies. Ann Transplantation 1997, 2:14-17.

54. Penn I: The effect of immunosuppression on pre-existing cancers. Transplantation 1993, 55:742-747.

55. Snow AL, Martinez OM: Epstein-Barr virus: evasive maneuvers in the development of PTLD. Am J Transplant 2007, 7:271-277.

56. Preiksaitis JK, Keay S: Diagnosis and management of posttransplant lymphoproliferative disorder in solid-organ transplant recipients. Clin Infect Dis 2001, 33 (Suppl 1):S38-S46.

57. Starzl TE, Nalesnik MA, Porter KA, Ho M, Iwatsuki S, Griffith BP, Rosenthal JT, Hakala TR, Shaw BW Jr., Hardesty RL: Reversibility of lymphomas and lymphoproliferative lesions developing under cyclosporin-steroid therapy. Lancet 1984, 1:583-587

58. York L, Qualtiere LF: Cyclosporin abrogates virus-specific T-cell control of EBV-induced B-cell lymphoproliferation. Viral Immunol 1990, 3:127-136.

59. Buell JF, Gross TG, Woodle ES: Malignancy after transplantation. Transplantation 2005, 80 Suppl:S254-264. 
60. Penn I: Primary kidney tumors before and after renal transplantation. Transplantation 1995, 27:480-485.

61. Penn I: Posttransplantation de novo tumors in liver allograft recipients. Liver Transpl Surg 1996, 2:52-59.

62. Yao FY, Xiao L, Bass NM, Kerlan R, Ascher NL, Roberts JP: Liver transplantation for hepatocellular carcinoma: validation of the UCSF-expanded criteria based on preoperative imaging. Am J Transplant 2007, 7:2587-2596.

63. Verdecchia A, Francisci S, Brenner H, Gatta G, Micheli A, Mangone L, Kunkler I; EUROCARE-4 Working Group: Recent cancer survival in Europe: a period analysis 2000-2002 of the EUROCARE-4 data. Lancet Oncol 2007, 8:784-796.

64. Berrino F, De Angelis R, Sant M, Rosso S, Lasota MB, Coebergh JWW, Santaquilani M, EUROCARE Working Group: Survival for eight major cancers and all cancers combined for European adults diagnosed in 1995-1999: results of the EUROCARE-4 study. Lancet Oncol 2007, 8:773-783.

65. Eisenhauer EA, Therasse P, Bogaerts J, Schwartz LH, Sargent D, Ford R, Dancey J, Arbuck S, Gwyther S, Mooney M, Rubinstein L, Shankar L, Dodd L, Kaplan R, Lacombe D, Verweij J: New response evaluation criteria in solid tumours: Revised RECIST guideline (version 1.1). Eur J Cancer 2009, 45:228-247.
66. Loprinzi CL, DuVy J, Ingle JN: Postchemotherapy rheumatism. J Clin Oncol 1993, 11:768-770.

67. Creamer P, Lim K, George E, Dieppe P: Acute inflammatory polyarthritis in association with tamoxifen. Br J Rheumatol 1994, 33:583-585.

68. Vogelzang NJ, Bosl GJ, Johnson K, Kennedy BJ: Raynaud's phenomenon: a common toxicity after combination chemotherapy for testicular cancer. Ann Intern Med 1981, 95:288-292.

69. Papamichael D, Amft N, Slevin ML, D'Cruz D: 5-Fluorouracil-induced Raynaud's phenomenon. Eur J Cancer 1998, 34:1983.

70. Swaneveld FH, van Vugt RM, de Boer JP, Dijkmans BA, Lems WF: A 57-yearold man who developed arthritis during R-CHOP chemotherapy for nonHodgkin lymphoma. Clin Rheumatol 2008, 27:249-251.

doi:10.1186/ar3352

Cite this article as: Elandt K, Aletaha D: Treating rheumatic patients with a malignancy. Arthritis Research \& Therapy 2011, 13:223. 